\title{
SYNTACTIC CONSTRAINTS ON RELATIVIZATION IN JAPANESE
}

\author{
SIRAI, HIDETOSI \\ School of Computer and Cognitive Sciences \\ Chukyo University \\ 101 Tokodate, Kaizu-cho, Toyota, Aichi, Japan 470-03 \\ TOMIOKA, YUTAKA \\ Faculty of Engineering \\ University of Tokyo \\ 7-3-1 Hongo, Bunkyo-ku, Tokyo, Japan 113
}

\begin{abstract}
This paper discusses the formalization of relative clauses in Japanese based on JPSG framework. We characterize them as adjuncts to nouns, and formalize them in terms of constraints among grammatical features. Furthermore, we claim that there is a constraint on the number of slash elements and show the supporting facts.
\end{abstract}

\section{Introduction}

This paper discusses the formalization of relative clauses in Japanese based on JPSG (Japanese Phrase Structure Grammar)[1, 2], which is a constraintbased grammar formalism like IIPSG(Head-driven Phrase Structure Grammar)[7, 8]. We have worked on JPSG with Prof. Gunji, and also have developed a parser based on an efficient mechanism for dealing with constraints $[3,4,10]$ to show that JPSG is effective even for the computational processing of natural language.

In the next section, we briefly introduce JPSG theory. Following a simple characterization of relative clauses in Japanese language in section 3 , we disscuss the variety of acceptability in secton 4 , and describe its formalization in terms of constraints among the grammatical features in section 5 . And in section 6 we will claim that there is a constraint on the number of slash elements and show the supporting facts.

\section{Basics of JPSG}

This section describes a brief introduction to JPSG, which is a grammar formalism originally for the Japanese language. As with HPSG, JPSG is feature based and constraint based grammar.

\subsection{Features}

Grammatical categories are represented as sets of features. We list the features used in this paper.

(1) Features used in this paper pos (part of speech) same as in IIPSG.

gr (grammatical relation) takes either $s u b j, o b j$, or iobj as the value.

subcat (subcategorization) designates the set of categories (complements) that a particular category (head) requires. Though we have to distingush two types of complements (ie., agglutinated or not) in Japanese, for simplicity, we assume that subcat designates the both types of complements.

dep (dependent) designates the category that a particular category (adjunct) modifies.

core roughly corresponds to CAT feature in HPSG [8]. The value is a set of features including subcat feature and so-called head features such as pos, gr and dep.

slash designates a syntactic gap within the grammatical category involved.

sem (semantics) designates the semantic representation of the grammatical category involved.

In this paper, categories are designated by a left square bracket ("[") followed by an indefinite number of feature specifications (a feature name followed by its value) separated by commas(",") followed by a right square bracket (")"). When the value is nul! or not relevant, the entire feature specification can be omitted. The sharing structure is indicated by variables such as $X, Y, \ldots$, which is distinguished by an initial capital letter as in programming language Prolog. Finally, a category of the form [core fpos $c_{t}$ $\ldots\}, \ldots$, sem $s]$ is often abbreviated as $c[\ldots]: s$.

Because grammatical relations play no role in ordering complements in Japanese, we assume only a binary-branching phrase structure schema as seen in the next subsection.

\subsection{The Phrase Structure Schema and Gram- matical Principles}

We are assuming three basic phrase structure schema for Japanese: complementation, adjunction, and co- 
ordination:

(2) a. Complementation

$$
\begin{aligned}
& \mathrm{M} \rightarrow \mathrm{CH} \\
& \mathrm{M} \rightarrow \mathrm{H} \mathrm{H} \\
& \mathrm{M} \rightarrow \mathrm{H}_{1} \mathrm{H}_{2}
\end{aligned}
$$$$
\text { b. Adjutuction }
$$$$
\text { c. Coordination }
$$

where $M$ stands for an arbitrary mother category, $C$ a complement, II a head category, and $\mathbf{A}$ an adjunct. Each category is construed as complex symbols, or features, with internal structures. 'The above structures are uniquely characterized by the features. For example, the head in the complementation structure should have subcat feature one of whose value is unified with the complement, $\mathrm{C}$.

Furthermore, we assume the following grammartical principles, which are applied to every structures:

Head Feature Principle: sane as in IIPSG. We assume that pos, dep, and other several features are head features.

Subcat Feature Principle: In the complementation structure shcema (2b), the value of subcat of the mother category unifies with that obtained by subtracting the left daughter category from the value of subcat of the head category. In the other strucrues, the value of subcat of the mother category unifies with that one of the head category.

Binding Feature Principle: The value of a binding feature of the mother category unifies with the union of its value of the left daughter category and its value of the head category minus the category bound of this local branching ${ }^{1}$. We assume that slash and some other features are binding features.

Slash feature and Binding Feature Principle play a crucial role in describing so-called long distance dependency phenomena. We will discuss them in detail in the following sections.

\section{Relative Clauses in Japanese}

Traditionally the relative clause in Japanese has been considered as a kind of so-called ren-tai syusyoku setu 'the clause for modifying noun'. Because it is characterized as an embedded sentence for modifying the liead noun in the structure [s ...]N, it can be consid. ered as an adjunct to the head noun.

In this paper, we adopt this idea. Thus, the structure of relative clause-head noun construction can be described as shown in Figure 1, where the left daughter category is a relative clause, and the right daughter category is a head noun. The fact that the left daughter category has dep feature whose value

\footnotetext{
${ }^{1}$ For example, when the left daughter and the head daugliter have $\{A\}$ and $\{B\}$ as their glash feature value respectively, the value of slash of the mother will be $\{A, B\}$ in most cases. However, in case that $A$ can be unifiable with $B$, the result can be $[A]$. Furthermore, in case that $A$ (or $B$ ) is bound in the local branching atructure (as in Figure 4), the result will be ( B \} (or $\{A\})$.
}

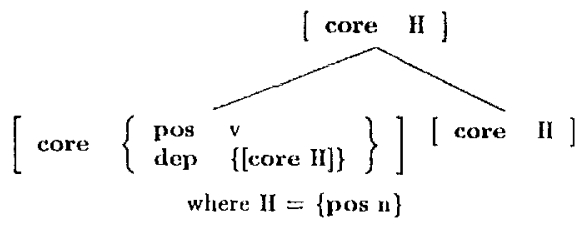

Figure 1: Relative Clause as Adjunct

is unifiable with the right daughter category, characterizes the left daughter (ie. relative clause) as an adjunct.

However, we have to explain where this dep feature cones fron. In Japanse, a relative clause has a tense form at its enci. 'Thus we assume that tense form is categorized as a verb which takes a verb category as its complement. Furthermore, we assume that for every tense form (e.g. - ta and -ru), there are two different Jexical entries with the same phonetic form, which we call the prenominal tense form and the assertive tense form ${ }^{2}$. The former type is assumed to be the ending form of relative clauses, and has a non-null value in dep feature. This value is bound with the head noun of the relative clause ${ }^{3}$.

\section{Types of Relative Clauses}

Relative clauses can be classified into the following three types in terms of their structural characteristics (where $\phi$ marks a gap):

1. SS: Simple Sentence

The relative clause consists of a simple sentence, and the gap plays a role in that sentence, e.g

(3) [Naomi-ga $\phi$ yom-da] hon NOM $A C C$ read PAST book

'the book which Naomi read'

2. FS: Embedded Sentence

The relative clause includes an embedded sentence in which the gap plays a role, e.g.
(4) [Naomi -ga ['Taro-ga $\phi$ yom -da] NOM NOM ACC read PAST -to sinzitei -ru ] hon

CMPI, believe PRES book

'the book which Naomi believes Taro read'

3. RC: Relative Clause

The relative clause includes a relative clause in which the gap plays a role, e.g.

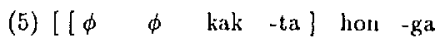
NOM ACC write P'AS' book NOM yoku ure -ta ] sakka well sell PAST writer 'the writer whose book sold well'

\footnotetext{
${ }^{2}$ I'here are several reasons why we caul sasume there are two different lexical entries for tense with the sarne phonetic form [9].

3ro assertive tense form is assumed to be the ending form of assertive clauses, and has a null value in dep feature.
} 
Table 1: Acceptance of Relative Clause

\begin{tabular}{|l|c|c|c|}
\hline Grammatical Role & SS & ES & RC \\
\hline Subject & $\circ$ & 0 & $\circ$ \\
Object & $\circ$ & $\circ$ & $?$ \\
Adjunct 1 & $\circ$ & $\circ$ & $?$ \\
Adjunct 2 & $*$ & $*$ & $*$ \\
\hline
\end{tabular}

Table 2: Simplification of Judgement

\begin{tabular}{|l|c|c|c|}
\hline Grammatical Fole & SS & ES & RC \\
\hline Subject & 0 & 0 & 0 \\
Object & 0 & 0 & 0 \\
Adjunct 1 & 0 & $\circ$ & 0 \\
Adjunct 2 & $*$ & $*$ & $*$ \\
\hline
\end{tabular}

As Inoue $[5,6]$ pointed out, the acceptability of the relative clauses varies depending on their types shown above and what roles are played by the gaps.

The grammatical roles other than subject and object can be classified into the following two types depending on the acceptability of relative clauses shown in Table1, where, o, ? and * represent our subjects' judgements are acceptable, marginal, and unacceptable, respectively. :

Adjunct 1 : This includes 'locative'(marked by ni, wo and de), 'goal'(marked by ni and he) and 'source'(marked by kam).

Adjunct 2: This includes 'instrumental'(marked by de), 'reason'(marked by kara) and 'comparative'(marked by yori).

In order to simplify the formalization, we will regard the marginal cases as acceptable, and the result is shown in Table 2. This simplification, however, may be too permissive, because usually in the $\mathrm{RC}$ clauses are acceptable only when the gap's role is subject.

\section{Formalization}

In this section we will formalize the syntactic structure of the relative clause in Japanese. First we will formalize the SS type relative clause. Then we formalize the distribution of the slash feature. And finally, we examine the other cases, that is, those in which the gap is derived in either an embedded sentence or a relative clause.

\subsection{Simple Relative Clause}

As discussed in section 3 , a relative clause is regarded as an adjunct. Thus, the gap should be bound with the dep feature value of the prenominal tense category.

As shown in the last section, gaps are not restricted to subjects or objects. Optional Adjunct 1 categories ('locative','goal' and 'source') can be a gap. Thus, for simplicity, we here assume that Adjunct 1 type roles are also designated in the value of subcat feature.

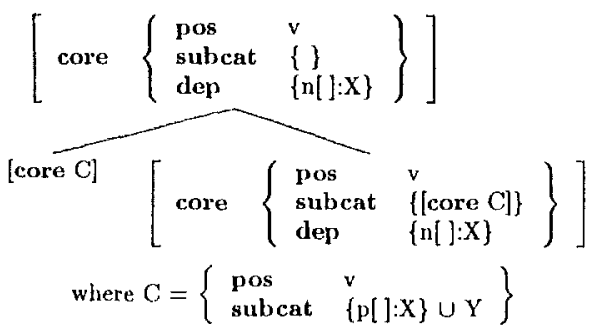

Figure 2: Binding of Dep with Subcat

Furthermore, we assume that a gap is directly bound with dep feature, instead of being bound with an element of slash which is in turn bound with dep. We call this hypothesis the Direct Binding Hypolhesis (that is, subcat element can be directly bound with dep). We will discuss the correctness of this assumption in section 6 .

This relationship is expressed in the lexical entry for prenominal tense category, eg. $\sim t a_{1}-r u$, and $-i$. The structure is shown in Figure 2, where the head daughter is a prenominal tense category. For example, kak 'write' is assumed to take both subject and object complements and have the following lexical cntry as follows:

(6) $v[$ core $\{$ subcat $\{\mathrm{p}[\mathrm{gr}$ subj]:X, $\mathrm{P}[\mathrm{gr}$ obj]:Y\}\}]

Then, a relative clause kak-ta 'wrote' corresponds to the following categories:

(7) a. v[core $\{$ subcat \{\}$, \operatorname{dep}\{n[g r$ subj $\}\}\}]$

b. v[core $\{$ subcat \{\}$, \operatorname{dep}\{n[g r$ obj $]\}\}]$

Thus for kak-ta $\mathrm{X}$ (where $\mathrm{X}$ is a noun), there are at least two possibilities in the interpretation of the role of $\mathrm{X}$, that is, either subject or object.

\subsection{Distribution of Slash}

As sentence (5) shows, there is a so-called longdistance dependency phenomenon in Japanese. This phenomenon is described by using the slash feature as in IPPS. We will characterize the distribution of slash in the following three sections.

\subsubsection{Slash Introduction}

Lexical entries with non-null value in slash feature are introduced by the following lexical rule: ${ }^{4}$

Subcat-Slash Lexical Rule:

[subcat $\{\mathrm{p}[]: \mathrm{X}\} \cup \mathrm{S}]$

$\Rightarrow[$ subcat $S, \operatorname{slash}\{n[]: X\}]$

The number of slash elements introduced by this rule can be at most one, a fact which we explain more precisely in the next section.

\footnotetext{
4 There are some restrictions on the application of this rule. For example, an agghtinated complement cannot becone a slash value.
} 
For example, kak 'write' will have the following lexical entries other than (6) by this lexcial rule:

(8) a. $v[$ core $\{$ subcat $\{\mathrm{p}[\mathrm{gr}$ subj]:X\}\}, slash $\{n[g r$ obj]:Y\}]

b. $v[$ core $\{$ subcat $\{p[g r$ obj]:Y $\}\}$, slash $\{n[g r$ subj]:X $\}]$

\subsubsection{Slasi INHERITANCE}

Each slash inheritance is constrained by means of Binding Feature Principle. Here, again, we assume that the number of slash elements of each category can be at most one.

In the RC type relative clause, the gap is inherited from the innermost embedded clause to the outermost relative clause shown in Figure 3.

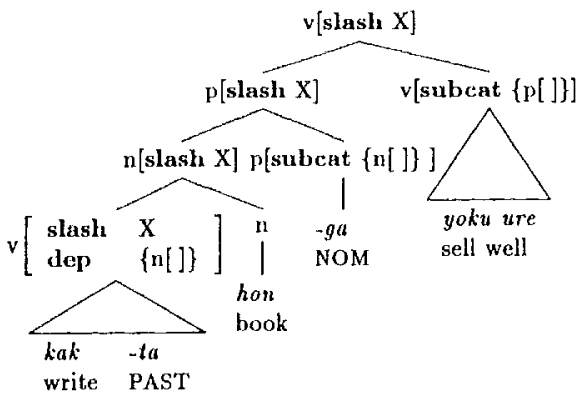

Figure 3: Example of Slash Inheritance

\subsubsection{SLASH BINDING}

A long-distance inherited gap can be bound with the dep of the prenominal tense category, and finally bound with the head noun of the relative clause as shown in Figure 4 (where only core features of the mother and the head are shown). For example, if the left daughter category corresponds to kak-ta honga yoku ure 'book which $\phi$ wrote sells well'), and the right daughter (i.e. the head) to the prenominal tense form -ta, then the mother, kak-ta hon-ga yoku ure-la, will be described as follows:

$$
\text { v[core }\{\text { dep }\{n[]\}\}]
$$

It should be noted that we do not necessarily need a specific phrase structure rule for the slash binding with the dep [9], though it may be natural that we assume to have such a phrase structure rule as shown in Figure 4.

\subsection{Complex Relative Clause}

In both $\mathrm{ES}$ and $\mathrm{RC}$ type relative clauses, the Binding Feature Principle specifies that a slash element which is introduced by the Subcat-Slash Lexical Rule is inherited and finally bound with the dep value of the prenominal tense category in the outermost relative clause. Figure 5 shows an example of such a structure.

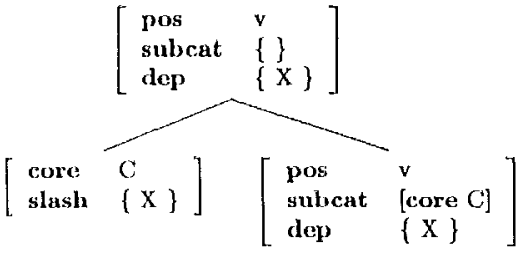

Figure 4: Slash Hinding

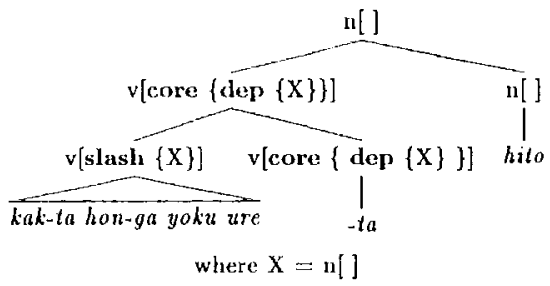

Figure 5: Complex letative Clause

\section{Constraints on the Number of Slash Elements}

As the consequence of the constraints on slash shown above, an Adjunct 2 type role cannot construct any acceptable relativization, because it cannot introduce an element of subcat in any lexical entries.

As discussed in section 3 , we assume the relative clause of Japanese language is an adjunct. Thus in the relative clause, the value of the dep feature is bound with the gap. And according to the Direst Binding Hypothesis which we proposed in section 5, a sulucat element can be directly bound with the dep. Ilere, we will discuss why this hypothesis is correct. Furthermore, we will show that if we adopt the Direct Binding Hypothesis, the number of slash elements can be at most one.

If we don't accept this hypothesis, the only alternative is to assume that the gap is bound only with an element of slash. That is, if an element of subcat cannot be bound directly with the value of the dep, the gap should be initially in the value of slash, and should then be bound with the element of dep. We will call this hypothesis the: Indirect Binding Hypothesis (that is, subcat element can be indirectly bound with the dep through a lexical rule).

First consider the following sentence:

(9) [[ kak -ta] hon -wo syuppan-si -ta ] write PAST book ACC publish PAST syuppansya-ga yuumei -ni nar publisher NOM famous GOAL become -ta ] gakusya PAST scholar 'the scholar such that the publisher that published his book becane famous' 
This is acceptable to everyone. If we accept the Indirect Binding Hypothesis, the number of slash elements would be at least two, because in the above, every relative clause other than outermost one has at least two slash elements.

However, consider the following structures (where $i$ and $j$ are either 1 or 2 , and $\phi_{1}$ and $\phi_{2}$ are assumed to be bound with $N_{1}$ and $N_{2}$, respectively):

(10) a. Double Relative Clause

$I_{s}\left[s \ldots\left[\left[_{s} \ldots \phi_{i} \ldots\right] \mathbf{N} \ldots\left[_{S} \ldots \phi_{j} \ldots\right] \mathrm{N} \ldots\right] \mathrm{N}_{2} \ldots\right] \mathrm{N}_{2}$

b. Double Gap in one Relative Clause

[s $\left.\left.{ }_{s}\left[s \ldots \phi_{i} \ldots \phi_{1} \ldots\right] \mathrm{N} \ldots\right] \mathbf{N}_{2} \ldots\right] \mathbf{N}_{1}$

c. Embedded Sentence in Relative Clause

$\left[s l_{s} \ldots \phi_{1} \ldots\left[s \ldots \phi_{2} \ldots\right]\right.$ to $\left.\left.\ldots\right] \mathbb{N}_{2} \ldots\right] \mathbb{N}_{1}$

The following are example sentences with the above structures:

(11) a. Double Relative Clause (10.a)

$\left[\left[\left[\phi_{1}\right.\right.\right.$ kak -ta $]$ e $\quad$ ga $\left[\phi_{2}\right.$ mae-ni paint PAST picture NOM before

tor -ta ] syasin-ni nitei -ta ]

take PAST photo DAT resemble PAST

syasin-ka - -ga $\sin -\mathrm{da}]$ gaka $_{1}$ plotographer NOM die PAST painter 'the painter such that the photographer died whose photo taken before resembled the picture that he painted'

b. Double Gap in one Relative Clause (10.b)

[l[ $\phi_{1} \phi_{2} \phi_{3}$ kaka -se -ta $]$ gakusya $-g a$ write make PAST scholar NOM

sin -da ] hon 3 -ga yuumei-ni

die PAST book NOM famous DAT

nar -ta] hensyusya

become PAST editor

'the editor who made the scholar who died write a book that became famous'

c. Embedded Sentence in Relative Clause (10.c) [[ $\phi_{1}\left[\phi_{2}\right.$ syuwai-si -ta $]$-to kak -ta $]$ take-bribe PAST CMPL write PAST

seizikan -ga zisatu-si -ta] kisya politician NOM kill-himself PAST journalist 'the journalist who wrote a report that the politician, who killed himself, took a bribe'

Though the sentence (11.c) is better than the others, these are all unacceptable. Taking Indirect $B$ inding Hypothesis, the number of slash elements for the above is 3,3 , and 2 , respectively. It follows that in terms of the number of slash elements, we cannot explain the difference of the acceptability of the above structures.

However, we accept the Direct Binding Hypothesis, sentence (9) needs only one slash element, and sentences (11) all need at least two. Thus the Direct Binding Hypothesis is better than the Indirect Binding Hypothesis. And adopting this hypothesis leads to the concusion that the number of slash elements should be at most one.

\section{Concluding Remarks}

We have described a grammatical formalization of the relative clause in Japanese. Based on the JPSG framework, this formalization is characterized in terms of constraints, that is, relationships among the grammatical features in a phrase structure and information in the lexical entries. In this paper we proposed the Direct Binding Iypothesis, and showed that the number of slash elements should be at most one in Japanese.

Acknowledgments. We are grateful to Dr. Takao Gunji, Dr. Kóiti Hasida and other members of the JPSG working group at ICOT for discussion. And we thank Dr. Phillip Morrow for proofreading.

\section{References}

[1] Gunji, T. : Japanese Phrase Structure Grammar: A Unification-based Approach, D. Reidel, 1987.

[2] Marada, Y., Gunji, T., Miyoshi, H., Sirai, H. and Hasida, K. : JPSG-A Phrase Structure Grammar for Japanese, Advances in Software Science and Technology, Vol, 1, No. 1, 1989, pp. 1-15.

[3] Hasida, K. : Conditioned Unification for Natural Language Processing, Proc. 11th Int. Conf. on Comput. Linguistics, 1986, pp. 85-87.

[4] Masida, K. and Sirai, II. : Conditioned Unification, Comput. Softw., Vol. 3, No. 4 (1986) pp. 28-38 (in Japanese).

[5] Inoue, K. : Transformational Grammar and Japanese language, Taishukan, 1976 (in Japanese).

[6] Inoue, K. : Grammar Rules of Japanese language, Taishukan, 1978 (in Japanese).

[7] Pollard, C.J. and Sag, I.A. : Information-Based Syntax and Semantics, Vol. I: Fundamentals, CSLI Lecture Notes No. 12, Center for the Study of Language and Information, Stanford University, 1988.

[8] Pollard, C.J. and Sag, I.A. : Information-Based Syntax and Semantics, Vol. 2, to be published.

[9] Sirai, II. : Relative Clause and Adnominal Clause in Japanese, in preparation.

[10] Tsuda, H., Hasida, K. and Sirai, H. : JPSG Parser on Constraint Logic Programming, Proc. of th ACL European Chapter, 1989, pp. 95-102. 
Abstract, in Japanese

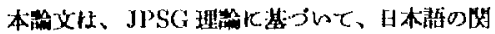

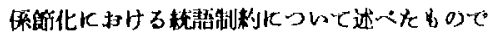
ある

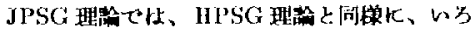

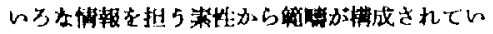

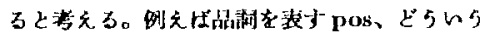

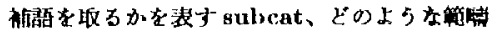

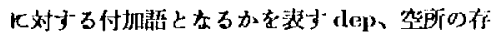
佂を表与 slashなどの慗性炕よってもれもれ

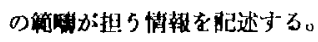

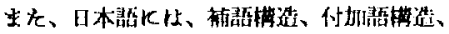

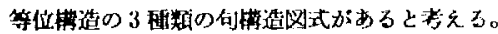

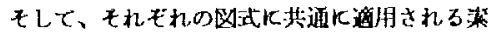

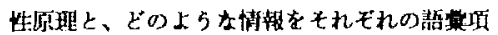
目が担っているかといちととから、さむざま

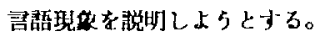

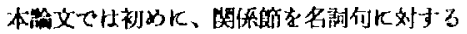

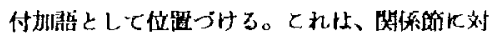

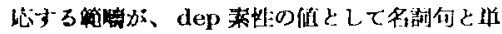

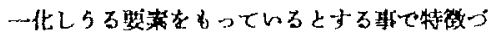
けられる。そして、とのdep 莱性は、閃係䬣在

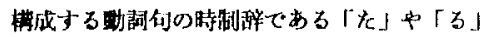

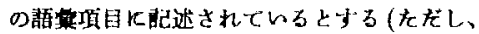

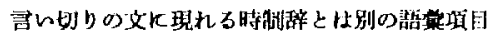

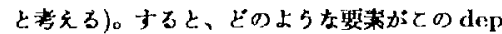

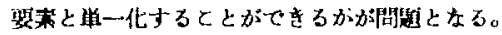

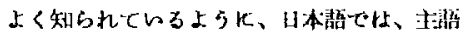

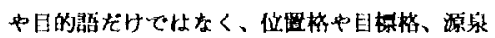
格左ども成係節化される。徒って我なト、との

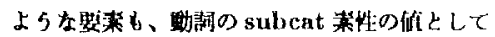
杞述されると考える。しかし、道其格中理山格、

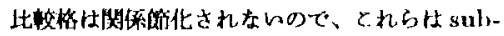
cat 翼来比含めないとする。

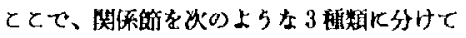
解析子る。

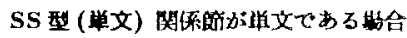

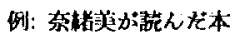

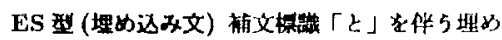
込久文中к空䜣がある期合

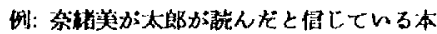

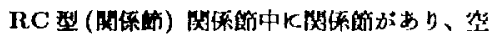

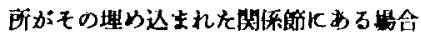

例: 害いた本がよく売れた作家

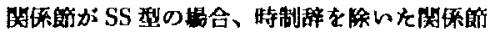

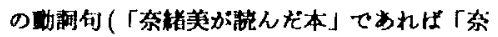
緒美が范ん」)の subcat の裂案の一つが時制

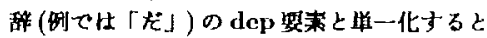

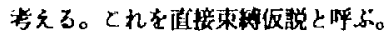

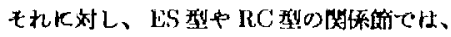

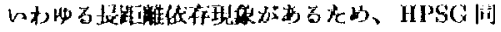

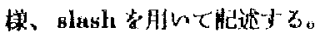

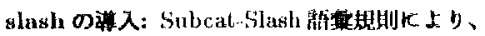
subcat $0-\cdots$ り得名。

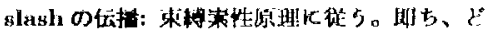

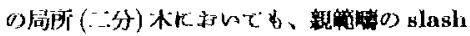

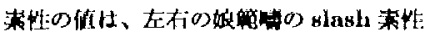

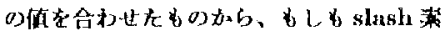

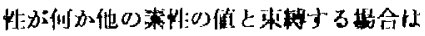

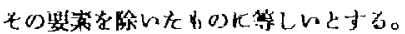

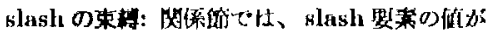

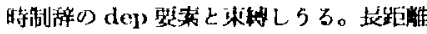

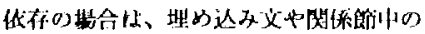

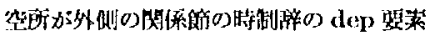

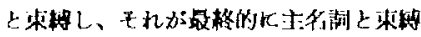
すると将え。

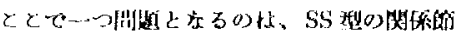

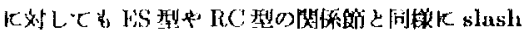

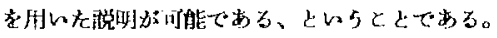

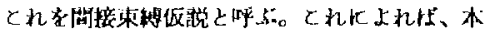

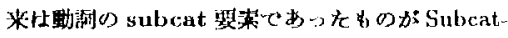

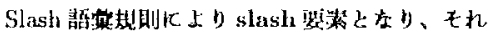

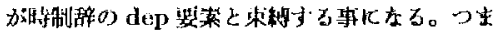

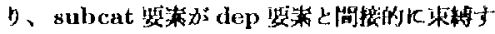
3。

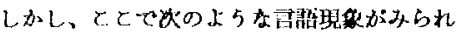
る。それね、

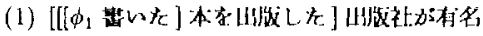
K去打学者

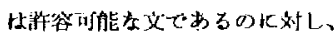

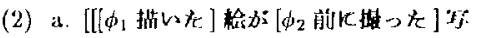

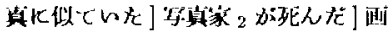
客 1

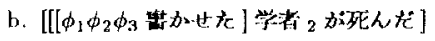

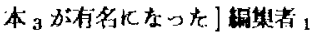

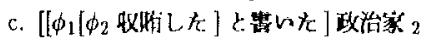

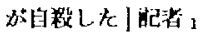

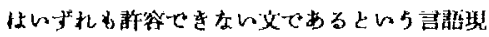

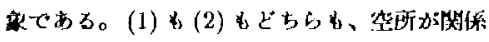

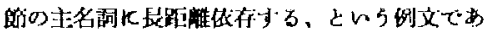
S。

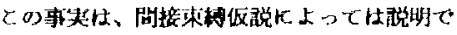

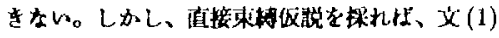

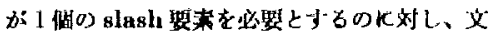

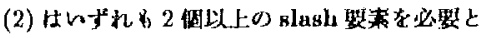

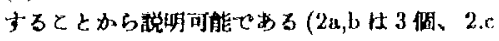

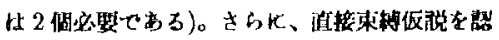

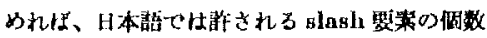

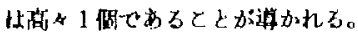

